\title{
DO INSTITUTIONAL CULTURES SERVE AS IMPEDIMENTS FOR WOMEN'S ADVANCEMENT TOWARDS LEADERSHIP IN SOUTH AFRICAN HIGHER EDUCATION?
}

\author{
N. Toni \\ Teaching and Learning \\ Nelson Mandela University \\ Port Elizabeth, South Africa \\ e-mail: noluthando.toni@mandela.ac.za
}

\section{A. L. Moodly}

Registrar

Rhodes University

Grahamstown, South Africa

e-mail: a.moodly@ru.ac.za

\section{ABSTRACT}

The South African higher education sector has undergone various changes over the past 24 years. As far back as 1997, several policies that advocated for equity and redress were introduced. The introduction of these policies, in conjunction with the Employment Equity Act (1998), has not fully addressed the gender imbalances at executive management level in universities. This article delves into cultural and structural constructs in higher educational institutions that impact on women and leadership. It further explores how women in leadership describe the general organisational culture and the manifestations thereof. Critical realism is used as a theoretical lens to analyse the influence and impact of institutional cultures on women in leadership. Women leaders are confronted with the culture of exclusion in the form of male dominance, silencing of women's voices and male patterns of networking. The article further advocates for extended leadership programmes that are specifically designed for women to change the status-quo. Such programmes can only be effectively implemented within an organisational culture that embraces gender equality and actively pursues recognition of women as equal members of society and other institutions, including institutions of higher learning.

Keywords: institutional cultures, leadership, masculine environment, gender inequities, culture of exclusion, institutions of higher learning.

\section{INTRODUCTION}

The higher education context, the world over, continues to be described as a "masculine" environment where most women struggle to reach the highest echelons (De la Rey 1999; Britton 2000; Mabokela and Mlambo 2017). The underrepresentation of women in executive positions 
is in contrast to their visibility in larger numbers in the lower ranks of the academy. Lower academic levels and middle management positions, even in present times, are congested with women whilst their male counterparts dominate senior management levels, governance and the professoriate (O'Connor 2011, 84). In explicating the dominance of males at these levels in Irish universities, O’Connor $(2011,87)$ attributes the male-domination and marginalization of women to an organizational culture that is homosocial and conformist. Homosociability can be explained as the "tendency to select people just like oneself" (Shepherd 2017, 86). Within the setting of homosociablity and conformism, the organisational culture, in most institutions of higher learning, is also pronounced as competitive with key features such as "power bargaining, bullying harassment and spite" (Morley 1999, 5).

Statistics from the Department of Higher Education and Training (DHET) through the High Education Information Management System, popularly known as HEMIS data, show female enrolment numbers to be higher than their male counterparts at undergraduate levels in South African universities. The higher numbers are not only tied to formal access, but the success rates of female students are also higher than those of their male counterparts. Female students also enjoy higher participation rates at Master's level as compared to their male counterparts. Participation rates of female students take a downward slide at doctoral level. Though an in-depth analysis on the decline of participation rates of women at doctoral level is not a focus of our research, we can deduce that this phenomenon could impact on the limited number of women in executive leadership positions in higher education. A direct link can be found in the results of O'Connor's research conducted in Ireland. The majority of participants in O'Connor's $(2011,93)$ study took it for granted that women's ascendance to professor levels was a necessary condition for gaining access to senior leadership and management positions. This widely accepted prerequisite ignores the fact that only a limited number of women form part of the professoriate. Moreover, not all men at the apex of the academy in Ireland are professors. The prerequisite, therefore, has gendered implications.

In publications which form part of a project that looks into the experiences of women in leadership in higher education, Moodly and Toni (2015; 2017a, b, c) explored aspects of, among others, access to leadership, the availability of role models and voices of women in leadership. It is worth noting that even with the 2017 and 2018 appointments of women at two South African institutions (Nelson Mandela University and the University of Cape Town) into Vice Chancellor positions, women still constitute about 19 per cent of Vice Chancellors in South Africa. In Moodly and Toni (2017a) a framework was recommended for professional development of women in accessing leadership positions within this landscape. The basis for designing the Moodly-Toni framework was informed by a variety of factors that include 
perceived organizational biases against women, service leadership by women, and the need for support structures to assist the ascension of women to the apex of the academy. This article focuses on the few who have broken the proverbial glass ceiling and who have managed to reach executive positions. The authors have deemed it necessary to go beyond analysing factors that contribute to the lack of women reaching the highest office and examine the experiences of those who have managed to get closer or have reached those positions. The area of focus is the organizational cultures of these institutions as experienced by women executives who participated in the authors' study.

\section{THEORECTICAL FRAMEWORK}

Critical realism is used as a theoretical lens to analyse the influence and impact of institutional culture on women in leadership positions in higher education. The principles of critical realism provide an appropriate lens to explore factors that contribute to the low number of women in executive positions. Our analysis and interpretation of data is anchored on three principles of realism. The first principle is described by Wilson and McCormack $(2006,46)$ as "casual explanations". These explanations are used to offer insights into the social contexts within which they exist. This is about going beyond just explaining the existence of social phenomena, there is also a need to examine and understand the foundations of these phenomena. According to Kempster and Parry $(2011,107)$, phenomena do not only exist at the level of events and experiences, but also at a deeper level that may not be observable. This refers to reality or powers that "may not be capable of being observed through events but rather are interpreted and explored through an understanding of the interplay between agency and structure" (Kempter and Parry 2011,110). These unobservable powers or factors, as Alderson $(2016,3)$ explains, are only known in their effects and assist in the explication and understanding of the world. Institutional cultures as experienced and observed by female leaders fall into this realm; it is for this reason that critical realism is used as a theoretical navigational framework for the study.

The second principle refers to social reality as interpretative reality by social actors, while the third is about the evaluation of social reality (Wilson and McCormak 2006, 47). Understanding institutional cultures from the perspectives of participants therefore calls for traversing these principles of critical realism. Critical realists believe that underlying power structures, though not always obvious or consciously experienced, have an influence on people's realities (Kempster and Parry 2011, 110). Delving into the realities of women leaders is one way of navigating what proponents of social realism describe as that which is denied, absent or ignored (Alderson 2016, 6) or not adequately interrogated by society. Understanding 
organizational cultures through the realities of the participants contributes towards creating opportunities for emancipatory practices.

\section{INSTITUTIONAL CULTURE}

The terms institutional and organizational cultures are, in this article, used interchangeably. An organizational culture, in Mabokela and Ntwanano-Wawila's $(2004,401)$ view, is a social or normative glue that holds an organisation together. Higgins $(2007,107)$ adds an element of pedagogic communication in explicating the term. He refers to both elements (social and pedagogic) as norms that operate formally and informally, both in teaching as well as outside the classroom or formal interactions. Institutional cultures can be viewed as patterns of behaviours or experienced behaviours over a period of time. They are best explained through lived experiences or realities of members of the institution. It is, thus, our view that the perceived or shared norms of an institution could be beneficial to some and a hindrance or disadvantage to others.

The introductory section of this article refers to the masculinist nature of higher education institutions (HEIs) the world over. Ramphele $(2008,210)$ attributes this phenomenon to the fact that these institutions were founded by white males and ended up adopting very strong male cultures. In describing the South African higher education landscape, Ramphele (2008, 210) identifies a plethora of factors that she claims are embedded in the cultures of higher education institutions. Among these factors is sexism and authoritarianism. Higher education institutional cultures are also described by some (Robinson 1995; Mabokela 2002; Mabokela and Ntwanano-Wawila 2004) as a "chilly climate". The marginalization of women in leadership positions, the masculinist nature of the institutions as well as the so-called chilly climate speak to the reality of a miniscule number of women in executive positions even though they are in the majority within the sector. It goes without saying that attention needs to be given to practices and underlying factors that contribute to the slow pace of cultural change in the status-quo. Ramphele is of the view that transforming these cultures requires systematic processes. The principles of critical realism, as explained above, allow for exploration of events, experiences and the unobservable practices in order to understand the phenomenon and the realities of the participants.

O'Connor $(2011,84)$ describes the culture to be "premised on homosociability". Furthermore, referring to respondents from the United Kingdom, O'Connor $(2011,88)$ describes senior management as a "boys club" with men who "still prefer to work with men" thereby perpetuating patriarchal norms. This entails that the environment is perceived as portraying male lifestyles and priorities with a culture that is competitive, aggressive and 
individualistic, with male dominated patterns of networking and influence.

\section{PROBLEM STATEMENT}

The limited number of women in leadership positions in higher education is in contrast to the sentiments of a progressive and transformative policy framework. The principles of equity and redress as expressed in the Employment Equity Act (1998), Higher Education Act 101 (1997) and White Paper 3 (1997), among others, are minimal when it comes to women representation in executive leadership positions. This begs attention since women are in the slight majority, not only in higher education, but also in the population registry of the country. The Employment Equity Act advocates for redress in employment patterns to ensure equitable representation at all (our emphasis) occupational categories and levels in the workforce.

The under-representation of women in executive and senior management positions in South African universities persists regardless of progressive policies. Moodly and Toni (2015), explored inequity in the representation of women in leadership positions and the need for an increased number of role models. Moodly and Toni $(2017 \mathrm{a}, 148)$ continued with the theme of women's access to leadership in higher education and developed the Moodly-Toni framework for women's professional development (to contribute to efforts of supporting women's career planning towards executive leadership positions. This article draws on these publications, while focusing on data gathered on the journeys shared with the authors through in-depth interviews with women who are at Deputy Vice Chancellor (DVC) level. The article therefore addresses the following question: How do institutional/organisational structural, cultural and psychological-cultural constructs impact on women and leadership in higher education?

In order to fully explore the main research question and the aim of the study, the following sub-questions were explored:

- What are the cultural and structural constructs that impact on women and leadership in societies in which the higher education institutions (HEIs) are situated?

- How do women in leadership describe the general organisational culture and the manifestations thereof?

- How can HEIs facilitate the advancement of women in higher education leadership?

\section{LITERATURE REVIEW}

In the introductory section of this article, reference was made to the masculinist nature of higher education leadership as a contributory factor to the scarcity of women in executive management positions. The masculinist environment creates unfair expectations on those women who have 
managed to occupy executive positions to behave like their male counterparts. These women are expected to rise above the socially constructed norms of what Kele and Pietersen $(2015,13)$ refer to as "femaleness" in order to aspire to the socially prescribed role of a leader (Kele and Pietersen 2015, 13). It is important to note that, as highlighted in Moodly and Toni (2017c, 158), gender identification is not homogenous as not all women acknowledge "hegemonic cultural traditions".

According to Nguyen $(2013,125)$, the "think manager-think male" attitude is entrenched, especially among males. In the higher education sector, this phenomenon extends to the professoriate and Vice Chancellor positions. These perceptions serve as inhibitions for women's career advancements as it is assumed that they do not possess the requisite attributes associated with leadership. Although the study of Kele and Pietersen $(2015,14)$ describes women as strategic thinkers, stereotypical views that characterise women as affectionate, interpersonally sensitive, gentle and sympathetic contribute to prejudicial attitudes that serve as barriers to women in leadership and management (Nguyen 2013, 125). Men are easily accepted into these roles because they have the masculine traits that are associated with leadership. These masculine traits include, but are not limited to forcefulness, self-reliance, dominance and aggressiveness.

In exploring the gendered inequalities in organizational hierarchies in higher education, Morley $(2013$, 117) opines that women were absent from positions of power and influence because they lacked the knowledge of the "rules of the game". Moreover, she found women were unenthusiastic about getting themselves involved in self-promotional and competitive behaviours that are traditionally associated with men. This point is further advanced by Nguyen $(2013,127)$ who states that women demonstrate a lack of political competence, which can impede career progress. It is for this reason that Morley (2013) recommends women's engagement with what she calls the "hidden curriculum" of academia which includes the use of networks, persistence and political skills.

There are, however, contrasting views that dispute earlier research findings that executive leadership positions were unattractive to women and too demanding. Participants in Shepherd's (2017, 84) research expressed enthusiasm about leadership and saw management as an attractive career option. It is to be noted that although some women aspire to occupy these positions, they may apply "self-preservation strategies" that Shepherd (2017) describes as avoidance of "cruel optimism" of aspiring to something that is statistically unlikely to be achieved.

Structural issues, hiring patterns and gendered organizational cultures are contributory factors to the slow progress in addressing the low numbers of women in leadership positions. It is often noted that organizations tend to replace leaders with those that are similar to those 
who vacated the positions, an approach which Nguyen refers to as supporting "people like us" (Nguyen 2013, 126). Shepherd's study refers to research commissioned by a leadership foundation which revealed that women who applied for senior management positions were twice more likely than their male counterparts to be unsuccessful. Sweden, as reported by Peterson (2016), is among countries with the highest percent (43\%) of women who occupy Vice Chancellor positions. This highest number is against the 10 per cent of the European Countries reported in 2012. Further probing on what Peterson calls demographic feminization has led her exploration of the "glass cliff" metaphor. The "glass cliff" metaphor, according to Peterson $(2016,114)$, applies to situations where women are appointed to management positions under different or abnormal circumstances. These circumstances include when organizations or companies are facing some kind of crises. Taking on leadership in such circumstances is associated with risk and the negative consequence of the "glass cliff" denotes dangers of falling from the heights of leadership. It therefore flows from the foregoing that gender inequities in executive management continue to persist in higher education. As much as this is a global phenomenon, South Africa, a country with a progressive constitution and advanced policy framework, has not made any remarkable strides in transforming the gender imbalance in executive positions of the academy. A question that is worth pondering over when it comes to the "glass cliff" metaphor is whether the recent appointments of women at the two South African universities could be associated with this phenomenon. The 2015/16 era of \#FeesMustFall, and the burden of burning institutions have exhausted those in leadership, propelling women into an unstable and unpredictable environment - a high risk, high fall position.

\section{Implications of a lack of women leadership for higher education in general}

The "intentional preparation of future leaders for higher education" in recognition of the shortage of leadership in higher education, more particularly in terms of women is foregrounded by Madsen, Longman and Daniels $(2012,113)$. This is particularly critical, considering that "postsecondary institutions are struggling more than ever before" to identify persons with the necessary qualification, experience and skills to move into positions of leadership (Madsen 2012,3). Madison cites the former as one of the reasons for the development of women as "few women in higher education (are) positioned to take on such critical roles". Succession planning and sustainable leadership in higher education, as in all spheres of society, is key to the survival of the sector as a critical component of a culture which is knowledge-based and values knowledge - shaping, sharing and advancement. Sustainability in leadership is dependent on emerging leaders through professional development, inclusive of women. Not only do women often form the majority of the population in many countries (Chanana 2013; Grimshaw and 
Francis 2014; Muzvidziwa, 2015), including South Africa (Republic of South Africa 2017), but also as graduates at universities, the percentage of women obtaining higher degrees has "eclipsed" men (Longman and Lafreniere 2012, 46). From a mere quantitative perspective, neglecting the development of women towards leadership, would impact negatively on the higher education sector, and ultimately impacts on sustainability of a knowledge-based society. Moodly and Toni $(2017 \mathrm{c}, 157)$, argue that the ramifications of neglect of capacitating women in leadership are dire to the "socio-economic viability and sustainability" of a country. The authors further cite "principles of equity within a just and democratic society", in the context of the national transformation agenda, as imperatives towards affirming women "in all spheres" and at all "levels of society". Research reflects further that women also contribute to diversity in leadership and considering the challenges with which higher education is currently faced (White 2012; Jansen 2017), there is a need for a multiplicity of leadership styles, inclusive of caring, nurturing and teamwork forms associated with women (Muzvidziwa 2015).

\section{How does institutional culture undermine women leadership?}

The global phenomenon of institutional culture and the undermining of women and leadership, is reflected throughout literature (Madsen 2012; Nguyen 2013; Grimshaw and Francis 2014; Muzvidziwa 2015; Bulick and Frey 2017) and is also reflected in the introduction of this article. In a paper on decolonisation and transformational leadership, Moodly and Toni $(2017 \mathrm{c}, 156-$ 157), cite multiple authors in their description of South African universities' institutional culture as "gendered" 'as constructed through the colonialist ideology, valorising a EuroAmerican construct of leadership'. This form of leadership, valorises a patriarchal, male gendered perspective which by its very nature undermines women and women's ways of leadership, characteristically service-orientated, nurturing, caring, supportive and inclusive in nature. For these reasons, amongst others, women have often remained at the levels of middle management (the glass ceiling), with few breaking through. This phenomenon is also exacerbated by what Savigny $(2014,800-802)$ calls "cultures of gender bias" in British academia where women's CV's are harshly judged against male counterparts when applying for promotion. Savigny furthermore asserts that when men strive for promotion their ambitions are applauded whilst women's ambitions are negatively interpreted. Longman and Lafreniere (2012, 46), cite Myerson and Fletcher (2000) who assess and summarise university organisational culture in the following way:

"It's not the ceiling that's holding women back; it's the whole structure of the organizations in which we work: the foundation, the beams, the walls, the very air. The barriers to the advancement of women are not just above women, they are all around them ...." 
Longman and Lafreniere $(2012,47)$ state that these "male-normed organizational cultures are a contributing factor to the scarcity of women" in leadership.

\section{METHODOLODY AND DATA COLLECTION}

This is a qualitative study that is located in the interpretive paradigm. The interpretive tradition focuses on studying and understanding the fundamental nature of the social world at the level of subjective experience (Burrel and Morgan 1979, 28). The article draws extensively on qualitative interviews with three women at DVC level of leadership. The small sample is a consequence of the limited number of women in executive positions that are higher than the level of Faculty Dean. It is to be noted that requests for participation were sent to seven women at both Vice Chancellor (VC) and DVC levels. One VC, out of the two that were invited, initially agreed to participate in the study, but her availability later became a challenge and the scheduled interview had to be cancelled. The data collection process coincided with the \#RhodesMustFall and \#FeesMustFall protest actions in 2016 and that also contributed to the unavailability of targeted, possible participants. This led to participation of DVCs. Only three of the four DVCs who initially agreed to participate followed through with the face-to-face interviews.

The interviews were transcribed and sent back to the interviewees for self-check and comments, and subsequently corrections. Participants were further requested to indicate sections considered highly confidential for direct citation in publications.

\section{LIMITATIONS}

The small sample that came as a result of the explication above does not lend itself to generalization of findings. Institutional contexts and historical developments have a direct impact on the experiences of leaders. A bigger sample that includes more universities might yield different findings.

\section{FINDINGS}

The discussion on findings is informed by the themes that emerged from the broad interview points covered in the research questions around structural constructs and general organisational culture that impact on women leadership in higher education. Common threads from the transcripts were grouped under similar themes.

\section{Structural and environmental factors impacting on women leadership in higher education}


Data that emerged from the in-depth interviews do not show any concerted efforts, either by way of university policy formulation, or general practice, to facilitate the advancement of women into leadership. Two of the three participants (A and B) indicated that they were not aware of the existence of formal structures and policies designed for the development and support of women towards leadership within their respective institutions. The participants mentioned developmental programmes towards leadership that are housed in the Human Resources (HR) divisions of their institutions. They indicated that the only aspects that speak specifically to the development of women as leaders is support given to women to attend the Higher Education Resource Services, also known as the HERS leadership academy (HERSSA). Both participants were themselves linked to or involved either directly or indirectly with the academy. One participant went as far as describing herself as the "ambassador of HERSSA". These institutions send women to the academy annually. The practice of sending a select few to the HERS-SA academy does not emanate from any formal policy decisions. Developmental opportunities, which are encapsulated in the promotions and HR policies refer rather to all employees in the institutions. There are no specific policies, structures or institutional plans that speak specifically to women's development, preparation and advancement to ascend to positions in executive management, even though they are in the minority at this level.

The two participants (A and B) recognised and mentioned a need to design programmes at institutional level that would focus mainly on the development and encouragement of women to study further, improve their publication profiles, as well as find the courage to apply for senior positions. The support, in their view, should not necessarily be limited to those occupying academic positions, but should be inclusive of those who hold administrative roles in order to assist them to access promotional posts and proceed to the highest levels of their fields.

“... you know there were too many administrative support people but then they are not being provided a career pathway that at least promotes them to the next levels and, of course, women are even more at a disadvantage." Participant B

... we need people to mentor and to recognise women who are up and coming, and sometimes to really say no ... you got to stop what you're doing and whip some sense almost into doing what will get them somewhere ...." Participant A

\section{Culture of exclusion and the proverbial glass ceiling}

The traditional form of the glass ceiling phenomenon where women could only get to a particular level of leadership (for example, middle management) and not ascend further is no longer in existence. However, the new form of this phenomenon presents itself in the form of exclusion. Some women who ultimately make it to higher positions such as Faculty Deans and 
DVCs often find themselves in situations where their voices are either ignored, excluded or side-lined within crucial discussions. Participant $\mathrm{C}$ described this by saying "once you get to the position it doesn't mean that your voice is equal to the voices of men". She went further to indicate that Senate, the highest decision-making body, has more male domineering voices". Another participant (participant B) narrated an incident where her male counterparts took a decision about what needed to be done to avert a crisis in her portfolio without first discussing the matter with her.

“... but before I even could share with my colleagues what was happening to get their ideas, they were already telling me they already knew what had happened and they already were coming up with answers. You know, and these were male colleagues, so at the end of the day I was like, oh my goodness so who's the one who is in charge of this portfolio?" Participant B

Participant A expressed an observation around situations where women's voices are suppressed and spaces dominated by males. Senate was mentioned as one example of a formal space that is dominated by males in terms of composition as well as active participation during meetings. Another example related her experiences during the early stages of her career where social spaces, such as pubs and bars, were used to exclude women in conversations that might end up being part of formal discussions.

\section{“Insensitivity" towards women's social positioning (gendered roles/stereotyping)}

The academy does not take into consideration the effects on women, of child-bearing and being primarily responsible for their families. A case in point is the policy around rewards or incentives for research in Participant A's institution where the cut-off line (in terms of age) for junior research awards is 39 years. Participant A stated that she had unsuccessfully advocated for the clause to focus on the number of years in academia instead of putting an age limit.

“... a lot of women don't apply because if you have your children in your late 20's or early 30 's you are not going to be doing all of that stuff ...."

All three participants mentioned perceptions and anecdotal references to women's delayed advancement to higher positions being compounded by them (women) having prioritised their families. The traditional roles and responsibilities of child-bearing and caregiving to their own families, extended families or in-laws were seen as part of family and societal dynamics that need to be navigated by women in their families thus delaying their progress towards leadership. 
"We've had young Deans who were in their forties, early forties for example who have said they need to be able to be at home with their children or pick up their children from school and things like that. And it's a gender issue ... and I've been surprised at myself ... but I've been honest when I've said it. I don't think it's a gender issue. I think it's a family issue, that if your home living arrangements and your family situation doesn't enable you to take up what is required of you as a Dean in a senior leadership position, you know ... then it's not a gender issue for us, and I don't know if that has been a fair comment ...." Participant $C$.

“... I've seen that, I mean that we can sabotage ourselves, we can be our own worst enemies, we will make excuses about why we can't go to the next level ... most of them of course, have to do with traditional roles that we as women have as caregivers and responsibilities at home, you know, and sometimes with extended family or in-laws ...." Participant B.

\section{Patriarchal nature of the academy and the perceived "old boys club"}

The culture of male dominance in the leadership culture is also perpetuated by the absence of formal mentoring structures for women. This contributes to another form of exclusion that plays out in formal structures such as Senate as briefly mentioned earlier, and in "social spaces" such as pubs or bars being utilised for formal or business discussions. The phenomenon of the "old boys" network is seen to be still in existence, albeit in varying degrees depending on the institution. It is perceived to be more prevalent in some and covert in others. Participant A described the "old boys club" phenomenon in her earlier years in the academy as follows;

"I was on the periphery, but the business was being done at the bar - that's where the real decisions were being made, at the bar, and I couldn't, I couldn't, I wasn't a member. I couldn't access that space, so I was excluded on the basis of my previous history because ... I'd never gone into bars and pubs, I didn't know how to deal with those social spaces ...."

Participant $A$ is of the view that things have since improved because such forms of exclusion would not be tolerated by the highest office (the Vice Chancellor's). However, she opines that there are still certain forms of exclusions that are cultural and racial in nature and that are still in existence. To illustrate the point about racial exclusion, she referred to her ascension to the DVC post not being celebrated because of the colour of her skin. Her words were:

“... I was challenged in getting this position, not because of my gender but because of my skin colour. My appointment to this position was never celebrated, and sometimes I feel a little raw about that. I'm the first woman DVC in this university ... I think that's quite something, but we couldn't celebrate it because of the colour of my skin ...."

Participant $\mathrm{C}$ opined that the old boys' club was in existence in her institution. She justified her statement by saying: 
"... in senior meetings like in Senate and in Executive Committee of Senate and those kind of gatherings, one can definitely see the gendered male predominance."

Participant $\mathrm{C}$ echoed a sentiment that was expressed by Participant $\mathrm{A}$ about change and/or improvements that are driven from the highest office. In this particular case, the Vice Chancellor was described as a person who ensured that there was balance in terms of gender and race in his senior leadership team. This commendation, however, was accompanied by the observation that the desired change was not necessarily reflected in the overall organizational culture because of male dominance.

\section{Coping mechanisms for women leaders}

The participants demonstrated various ways of coping with the demands of their positions. They either tap into the dominant institutional culture of ways of doing things for their own benefit or delve into their personal traits. Participant A described the culture at her institution as "collegial". Leaders are not in a position to impose their views and decisions on other managers. To use the words of participant A, "The culture is you win people around through argument and you win their hearts and minds and they'll support you or not support you". In this particular case, the participant recognises and uses what is known and accepted in the institution. Participant $\mathrm{C}$ on the other hand expressed her authenticity by standing by her convictions and approaches regardless of the circumstances.

“... I try to be authentic and that means I will start a meeting, in a time of crises with a poem, when somebody thinks I should immediately be thinking about how to solve the crises."

“... it is important to bring the fullness of who you are into the space so that people feel support ...."

In one of the three institutions, it was reported that women had formed a women's network for the purposes of supporting each other.

"I think it (the network) was created by women who felt they needed this structure ...."

In participant B's institution, advocacy for addressing gender inequity comes from various groupings, such as, people from a particular discipline or area of research, units and forums of both staff and students. The \#FeesMustFall movement has also brought the plight of women advancement to the fore. This speaks to the limited number of formal programmes, despite the existence of legislation. 
“... there have been certain groupings that looked at issues of gender, gender equity as well as gender inequity and they have been located in different spaces, ... some of these focused on the empowerment of women and girls ...." Participant C.

\section{DISCUSSION}

The small sample, as alluded to in the limitations' section, does not lend the findings to being generalised. The findings, however, reflect realities and views of women which are also underpinned by literature. The university environment is still patriarchal - an extension and reflection of our society where women, who because of their supportive and caring natures, are relegated to the periphery of leadership. The absence of formal structures for supporting women to advance to executive positions is among the contributory factors to the slow progress of transforming gender equity in higher education leadership. Networking and support structures, therefore, are vital in foregrounding women's ways of doing that contribute, rather than diminish good leadership. Two of the DVCs had the opportunity to be on HERS-SA academy and are still active in it. There is an indication that the academy had contributed in their journeys towards leadership. This, and other examples, such as the need for mentoring and supporting women relayed by the participants, indicate how women rely on their own networks and generic developmental opportunities to affirm themselves as leaders. Though women are pushing through the barriers and attaining leadership roles, a contributory factor may be the fatigue experienced by those in leadership during the \#RhodesMustFall and \#FeesMustFall movements. The possibility of fatigue that emanates from these protest actions could lead to the realization of the "glass cliff" phenomenon. Institutional and societal pressures, through traditional family responsibilities whilst dealing with institutional cultures that are dominated by men, are still the reality of our society and societies internationally, as literature reflects. The culture of exclusion in the form of male dominance at the highest structures such as the Senate and voices of women being in the periphery continue to plague higher education in South Africa. This is exacerbated by the now covert "old boys club" and the male patterns of networking that exclude women. Changing the leadership to include women does not automatically change the institutional culture. There has to be impactful leadership and an active voice for institutional change at the highest level.

\section{CONCLUSION}

Though women are breaking through the glass barrier, they may be facing a glass cliff, given the context of the current higher education landscape. Institutional culture as manifested in patterns reflecting patriarchy is a reality in these institutions. Men and women, therefore, cannot ignore the importance of mentoring programmes, support networks, role models, driven by the 
implementation of policy that supports and drives the advancement of women in academic positions towards attaining their doctoral degrees, publishing and ultimately ascending to the highest offices. Women in administrative and academic support positions also need support, mentoring and extended leadership programmes that are specifically designed for them. Women are to be embraced as equal members of society, including the higher education sector, giving impetus to the realization of policy imperatives that emphasise transformation and gender equality. The current leadership of women should contribute to the transformation of both institutional and societal patriarchal cultures, guarding against the dangers of the glass cliff, which may be conveniently used to perpetuate the myth that women are not equal to the task.

\section{REFERENCES}

Alderson, P. 2016. International human rights, citizenship education, and critical realism. London review of Education 14(3): 1-12. Doi: https://doi.org/10.18546/LRE.14.3.01

Britton, D. M. 2000. The epistemology of the gendered organization. Gender and Society 14(3): 418434.

Bulick, N. and S. Frey. 2017. The working woman in higher education: Reflections of the past, hope for the future. Reference Reviews, 31(2): 1-7.

Burrel, G. L. and D. Morgan. 1979. Social paradigms and organisational analysis. London: Heinemann Educational Books.

Chanana, K. 2013. Leadership for women's equality and empowerment in higher education. India International Centre Quarterly, 39(3/4) (winter 2013 to spring 2013): 81-84.

De la Rey, C. 1999. Career Narratives of Women Professors in South Africa. Doctoral Thesis. University of Cape Town.

Grimshaw, P. and R. Francis. 2014. Academic women and research leadership in twentieth- century Australia. In Diversity in leadership. ed. J. Damousi, K. Rubenstein and M. Tomsic. ANU Press.

Higgins, J. 2007. Institutional culture as keyword. Review of Higher Education in South Africa. http://www.che.ac.za/documents

Jansen, J. 2017. As by fire: The end of the South African university. Tafelberg: Cape Town, South Africa.

Kele, T. and J. Pietersen. 2015. Women leaders in a South African higher education institution: Narrations of their leadership operations. International Journal of Sustainable Development 08(5): $11-15$.

Kempster, S. and K. W. Parry. 2011. Grounded theory and leadership research: A critical realist perspective. The Leadership Quarterly 22(2011): 106-120. Doi:10.1016/ j.leaqua.2010.12.010

Longman, K. A. and S. L. Lafreniere. 2012. Moving beyond the stained glass ceiling: Preparing women for leadership in faith-based higher education. Advances in Developing Human Resources 14(1): $45-61$.

Madsen, S. R. 2012. Women and leadership in higher education: Learning and advancement in leadership programs. Advances in Developing Human Resources 14(1): 3-10.

Madsen, S. R., K. A. Longman and J. R. Daniels. 2012. Women's leadership development in higher education: Conclusion and implications for HRD. Advances in Developing Human Resources 14(1): 113-128.

Mabokela, R. O. 2002. Reflections of black faculty in South African universities. The Review of Higher Education 25(2): 185-205. 
Mabokela, R. O. and K. F. Ntwanano-Mawila. 2004. The impact of race, gender, and culture in South African higher education. Comparative Education Review 48(4): 396-416.

Mabokela, R. O. and Y. A. Mlambo. 2017. Women, leadership and organizational culture in higher education: Leassons learned from South Africa and Ghana. In The changing role of women in higher education, ed. H. Eggins, 76-92. Comparative Perspective. Doi: 10.1007/978-3-31942436-1_4.

Moodly, A. and N. Toni. 2015. Women's acess to higher education leadership: Where are the role models? Journal of Social Sciences 45(1): 45-52.

Moodly, A. and N. Toni. 2017a. Accessing higher education leadership: Towards a framework for women's professional development. South African Journal of Higher Education 31(3): 138-153.

Moodly, A. and N. Toni. 2017b. Women's voices of and leadership in higher education: A South African perspective. Journal of Educational Studies 16(1): 184-198.

Moodly, A. and N. Toni. 2017c. Re-imagining higher education leadership - in conversation with South African female deputy vice-chancellors. Perspectives in Education 35(2): 155-167.

Morley, L. 1999. Organising feminisms: The micropolitics of the academy. New York: St. Martin's Press.

Morley, L. 2013. The rules of the game: Women and the leaderist turn in higher education. Gender and Education 25(1): 116-131.

Muzvidziwa, I. 2015. Women educational leaders and the empowerment of others. Journal of Sociology and Social Anthropology 6(3), 365-376.

Nguyen, T. L. H. 2013. Barriers to and facilitators of female Deans' career advancement in higher education: An exploratory study in Vietnam. Higher Education 66(1): 123-138. doi:10.1007/s10734-012-9594-4

O'Connor, P. 2011. Irish universities: Male-dominated? Limits and possibilities for change? Equality, Diversity and Inclusion: An International Journal 31(1): 83-96. Doi.org/ $10.1108 / 0261015211199236$

Peterson, H. 2016. Is managing academics “women's work"? Exploring the glass cliff in higher education management. Educational Management Administration \& Leadership 44(1): 112-127.

Ramphele, M. 2008. Laying ghosts to rest. Dilemmas of the transformation in South Africa. Cape Town: NB Publishers.

Republic of South Africa. 2017. Statistical release - Mid-year population estimates (July). Pretoria: South Africa.

Robinson, J. L. 1995. Racism or attitude? The ongoing struggle for black liberation and self-esteem. New York and London: Plenum Press.

Savigny, H. 2014. Women, know your limits: Cultural sexism in academic. Gender and education 26(7): 794-809. Doi:10.1080/09540253.2014.970977

Shepherd, S. 2017. Why are there so few female leaders in higher education: A case of structure or agency? Management in Education (31)2: 82-87.

White, J. S. 2012. HERS Institutes: Curriculum for advancing women leaders in higher education. Advances in Developing Human Resources 14(1): 11-27.

Wilson, V. and B. McCormack. 2006. Critical realism as emancipatory action: The case for evaluation in practice development. Nursing Philosophy 7: 45-57. 